\title{
Electrical \\ Double Layers \\ in \\ Biology
}




\section{Electrical \\ Double Layers \\ in \\ Biology}

Edited by

Martin Blank

Department of Physiology

Columbia University

New York, New York 


\section{Library of Congress Cataloging in Publication Data}

Electrochemical Society Symposium on Electrical Double Layers in Biology (1985:

Toronto, Canada)

Electrical double layers in biology.

"Proceedings of the Electrochemical Society Symposium on Electrical Double Layers

in Biology, held May 14-15, 1985, in Toronto, Canada"-T.p. verso.

Includes bibliographies and index.

1. Biochemistry-Congresses. 2. Bilayer lipid membranes-Congresses. I. Blank, Martin, date. II. Title.

QP517.B53S27 1985

$574.19^{\prime} 283$

85-31708

ISBN-13: 978-1-4684-8147-1

e-ISBN-13: 978-1-4684-8145-7

DOI: $10.1007 / 978-1-4684-8145-7$

Proceedings of the Electrochemical Society Symposium on Electrical Double Layers in Biology, held May 14-15, 1985, in Toronto, Canada

(C) 1986 Plenum Press, New York

Softcover reprint of the hardcover 1st edition 1986

A Division of Plenum Publishing Corporation 233 Spring Street, New York, N.Y. 10013

$$
\text { All rights reserved }
$$

No part of this book may be reproduced, stored in a retrieval system, or transmitted

in any form or by any means, electronic, mechanical, photocopying, microfilming, recording, or otherwise, without written permission from the Publisher 
PREFACE

A number of apparently unrelated phenomena in biological systems (e.g., biopolymer aggregation, cell-cell interactions, ion transport across membranes) arise from the special properties of charged surfaces. A symposium entitled "Electrical Double Layers in Biology", which took place at the Toronto meeting of the Electrochemical Society, 12-17 May 1985, focused on the common features of these phenomena. The papers presented at that symposium are collected here and they illustrate ways in which an understanding of electrical double layers can elucidate a problem in Biology. An example of this approach can be seen from the paper I presented on ion transport and excitation, where the "unusual" ion flows during nerve excitation are actually expected if one includes the effects of electrical double layers at membrane surfaces. Furthermore, the selectivity of the ion channels in these membranes can be better understood on this basis. Other presentations account for such observations as the changes in spacing between muscle proteins during contraction, the interactions of red cells to form rouleaux, the electrical properties of algal cell membranes, electrokinetic potentials during blood flow in arteries, etc.

I trust that these papers will indicate the value of electrochemistry in the study of biological systems, an area of research usually called Bioelectrochemistry, and will encourage biologists to use these ideas when approaching related problems.

Martin Blank

Biological Sciences Division

office of Naval Research 
CONTENTS

Donnan Potential and Surface Potential of a Charged Membrane and Effect of Ion Binding on the Potential Profile . . . . . . 1

S. Ohki and H. Ohshima

An Empirical Relation for the Surface Potential of

Phosphatidic Acid Monolayers: Its Dependence on

Calcium and the Role of Double Layer Theory . . . . . . . . 17

J. A. DeSimone, G. L. Heck, and S. K. DeSimone

A Fundamental Question about Electrical Potential Profile in

Interfacial Region of Biological Membrane Systems . . . . . . 31

V. S. Vaidhyanathan

The Effect of Water Polarization and Hydration on the Properties of Charged Lipid Membranes . . . . . . . . . 53

I. S. Graham, A. Georgallas and M. J. Zuckermann

Influence of the Surface Charge Distribution and Water Layers on the Permeability Properties of Lipid Bilayers . . . . . . 63

E. A. Disalvo and L. S. Bakás

Facilitation of Ion Permeability of Bilayer Membranes and their Phase Transition . . . . . . . . . . . . 77

I. R. Miller

Single Channel Conductance Changes of Desethanolamine-

Gramicidin through $\mathrm{pH}$ Variations . . . . . . . . . . . 91

R. Reinhardt, K. Janko, and E. Bamberg

Membrane Potential of Squid Axons . . . . . . . . . . . 103

S. Ohki

Electrical Double Layers in Ion Transport and Excitation • . . • 119

M. Blank

Electrical Double Layers in Pigment-Containing Biomembranes • • • 129

F. T. Hong and T. L. Okajima

Electronic Properties of Electroactive Bilayer

Lipid Membranes . . . . . . . . . . . . . . . . 149

H. Ti Tien, J. Kutnik, P. Krysinski, and Z. K. Lowjewska

Electron Transfer at Biological Interfaces . . . . . . . . . 167

A. Rejou-Michel, M. A. Habib, and J. O'M. Bockris 
Alterations in Electrical Double Layer Structure Due to

Electromagnetic Coupling to Membrane Bound Enzymes . . . . . 185

J. D. Bond and N. C. Wyeth

Transient Impedance Measurements on Biological Membranes:

Application to Red Blood Cells and Melanoma Cells . . . . . . 201

R. Schmukler, J. J. Kaufman, P. C. Maccaro,

J.T. Ryaby, and A. A. Pilla

Measurement of the Frequency-Dependent Impedance

across Natural Cell Membranes . . . . . . . . . . . . 211

S. M. Ross

Electrorotation of Single Cells - A New Method for

Assessment of Membrane Properties . . . . . . . . . 227

R. Glaser and G. Fuhr

Recent Studies on Electrokinetic Potentials

in Humans . . . . . . . . . . . . . . . . . . . 243

E. Findl, H. Guthermann, and R. J. Kurtz

Effects of pH Before and After Deep-Freexe Storage at

$-80^{\circ} \mathrm{C}$ on the Zeta Potentials of Bones . . . . . . . . . 257

W. K. Elwood, S. D. Smith, and H. E. McKean

Electrochemical and Macromolecular Interactions at

Red Blood Cell Surface . . . . . . . . . . . . 267

K. M. Jan and S. Simchon

The Myosin Filament, Charge Amplification and Charge

Condensation . . . . . . . . . . . . . . . 277

G. F. Elliot, E. M. Bartels, and R. A. Hughes

Donnan Potentials Generated by the Surface Charge on Muscle Filaments . . . . . . . . . . . . . . 287

E. W. April and R. A. Aldorty

Long-Range Electrostatic Forces in Cylindrical Systems:

Muscle and Virus Gels... . . . . . . . . . 301

B. M. Millman

Contributors . . . . . . . . . . . . . . . . . . 313

Index . . . . . . . . . . . . . . . . . . . 317

viii 